\title{
EL CONTROL DE CONSTITUCIONALIDAD Y CONVENCIONALIDAD EN EL PROCESO ARBITRAL URUGUAYO
}

\section{CONSTITUTIONALITY AND CONVENTIONALITY CONTROL IN URUGUAYAN DOMESTIC ARBITRATION}

\section{CONTROLE DE CONSTITUCIONALIDADE E CONVENCIONALIDADE NA ARBITRAGEM INTERNA URUGUAIA}

Dra. Camila Umpiérrez Blengio*

RESUMEN. El presente trabajo tiene por objetivo analizar la admisibilidad del control de constitucionalidad y convencionalidad en el arbitraje doméstico uruguayo. La Constitución establece que la vía de excepción de inconstitucionalidad, así como la vía de oficio, se deben plantear en un proceso "judicial", lo cual genera grandes desafíos interpretativos tanto para la doctrina como la jurisprudencia nacional. Se concluye que debe admitirse el control de constitucionalidad y convencionalidad tanto por la vía de excepción como la de oficio ante cualquier tribunal, ya sea estatal o arbitral, por tratarse de un principio básico del Estado de Derecho.

PALABRAS CLAVE. Uruguay. Arbitraje. Control. Constitucionalidad. Convencionalidad.

ABSTRACT. This paper analyzes the admissibility of constitutionality and conventionality control in Uruguayan domestic arbitration. The Uruguayan Constitution establishes that the control of constitutionality both ex officio or by any party filing an objection, must be raised in a "judicial" process, which generates great interpretive challenges both for national academic legal opinion and case law. It is concluded that the constitutionality and conventionality control must be admitted before any tribunal, whether state or arbitral, based on a rule of law.

KEYWORDS. Uruguay. Arbitration. Control. Constitutionality. Conventionality.

RESUMO. O objetivo deste artigo é analisar a admissibilidade do controle de constitucionalidade e convencionalidade na arbitragem interna uruguaia. A Constituição estabelece que a via de exceção de inconstitucionalidade, assim como a via ex officio, devem ser suscitadas num processo "judicial", o que gera grandes desafios interpretativos tanto para a doutrina quanto para a jurisprudência. Conclui-se que o controle da constitucionalidade ou convencionalidade deve-se admitir perante qualquer tribunal, seja estadual ou arbitral, com base no Estado de Direito. 
PALAVRAS CHAVE. Uruguai. Arbitragem. Controle. Constitucionalidade. Convencionalidade.

\section{INTRODUCCIÓN: EL PROCESO ARBITRAL URUGUAYO.}

El arbitraje es un proceso por el cual se somete un litigio o controversia (se plantea una determinada pretensión) por acuerdo de las partes, a un sujeto privado, ajeno e imparcial (árbitro o a un tribunal conformado por más de un árbitro ${ }^{1}$ ) que dicta una decisión (laudo) sobre la controversia, que es vinculante para las partes.

Al escoger el arbitraje, las partes optan por un proceso de resolución de controversias alternativo a la justicia estatal. Este proceso resulta admisible siempre y cuando verse sobre cuestiones disponibles, ya que el asunto debe ser arbitrable.

Como resume con claridad FRAGA PITTALUGA (2016): "El arbitraje es un instrumento a través del cual un tercero, denominado árbitro, revestido con determinados poderes, resuelve un conflicto de intereses, que recae sobre materias de libre disposición mediante un auto definitivo, denominado laudo, que adquiere vinculatoriedad $e$ inmutabilidad en un ordenamiento jurídico" (p. 7).

En nuestro país, el arbitraje doméstico se encuentra regulado en el Código General del Proceso (C.G.P.), en los arts. 472 a 507.

Este mecanismo de resolución de conflictos ajeno al Poder Judicial adquiere cada día mayor relevancia, especialmente en temas comerciales donde se suele pactar el arbitraje doméstico, por las ventajas que presenta (en particular, la celeridad, flexibilidad y confidencialidad).

En relación a la naturaleza del arbitraje, mucho se ha discutido en doctrina. En efecto, dado que el proceso se tramita ante órganos que no integran el Estado, se ha planteado el debate respecto a si se ejerce función jurisdiccional o si, por el contrario, la jurisdicción la ejerce únicamente el Estado y el arbitraje es un instituto que emana de la autonomía privada de las partes.

\footnotetext{
* Doctora en Derecho y Ciencias Sociales egresada de la Universidad de la República (UDELAR). Aspirante a Profesora Adscripta de Derecho Procesal, Facultad de Derecho, UDELAR. Cursando la Especialización en Derecho Procesal de la Facultad de Derecho, UDELAR. Miembro de la Asociación Uruguaya de Derecho Procesal Eduardo J. Couture (AUDP). Correo electrónico: camila.umpierrez@hotmail.com

${ }^{1}$ El Reglamento de Arbitraje del Centro de Conciliación y Arbitraje, Corte Internacional para el MERCOSUR, Bolsa de Comercio de Uruguay, establece en su art. 9, bajo el nomen iuris "Número de árbitros", que: "1) El tribunal arbitral estará constituido por uno, tres o cinco árbitros, según sea convenido por las partes. 2) En caso de que las partes no hubieran establecido el número de árbitros o de que no existiera acuerdo entre las mismas sobre este punto, se entenderá que el tribunal estará compuesto por un árbitro único. Sin perjuicio de esto, el Centro podrá designar un número mayor de árbitros, atendiendo a la complejidad y circunstancias del arbitraje”.
} 
Siguiendo a VESCOVI (1989):

Por ser un proceso en el cual se elige a una persona privada para investirlo de la función jurisdiccional, la naturaleza de este procedimiento responde a la de dicha función. Es decir que quien se otorga los poderes del juez los tiene por imperio de la ley y por voluntad de las partes. En la asimilación del árbitro al juez y su similar naturaleza corresponde decir que aquel tiene, también, jurisdicción en el sentido de poder decir el derecho de acuerdo con la etimología de término (p. 226).

Actualmente, no cabe duda que el árbitro es asimilado al juez estatal y, por ende, está investido de poder jurisdiccional. En efecto, más allá de que el proceso arbitral no se sustancia ante órganos del Poder Judicial, está fuera de discusión que cumple función jurisdiccional y que lo integran árbitros que cumplen la función del magistrado.

La gran diferencia entre el arbitraje y la justicia estatal es la carencia del imperio ("imperium"), de poder hacer ejecutar lo juzgado.

DE HEGEDUS (2000), siguiendo la distinción planteada por DEVIS ECHANDÍA (1984, p. 79 y ss.) sobre los poderes para ejercer la jurisdicción, señala que:

Los árbitros poseen el poder de decisión que comprende el de conocer la cuestión litigiosa y resolver definitivamente el conflicto llevado a su conocimiento y el de documentación e investigación. Y carecen, por un lado, del poder de coerción, y por lo tanto, no poseen la facultad de imponer forzadamente el cumplimiento de cualquier resolución que adopte durante la tramitación del proceso y por el otro, del poder de ejecución, y en tal sentido carecen de facultad de ordenar la ejecución de sus laudos, inclusive mediante el uso de la fuerza pública. (p. 152)

DE HEGEDUS (2000, p. 154) también releva que la carencia del "imperium" afecta el poder cautelar el árbitro. Aun cuando se considere que los árbitros poseen facultades en el orden cautelar y, por ende, pueden resolver sobre la admisibilidad y pertinencia del pedido de una cautela - en tanto está vinculado con el aspecto litigioso sometido a arbitraje (que no está prohibido por el ordenamiento jurídico) -, si la ejecución requiere coerción, el tribunal arbitral deberá solicitar la intervención del juez ordinario competente para que la efectivice.

En consecuencia, cuando en el proceso arbitral se requiere de la coacción, ya sea durante la tramitación del arbitraje (por ejemplo, para la conducción de un testigo) o para la ejecución del laudo arbitral, es menester recurrir a la intervención de la justicia estatal. Esta intervención del Estado no debe enfocarse desde el punto de vista de una intromisión 
en el proceso arbitral, sino que se trata de un deber de colaboración y/o asistencia del Estado para con los tribunales arbitrales.

En conclusión, y sin perjuicio de esta carencia respecto de poder ejecutar lo juzgado ("imperium"), el proceso arbitral es un proceso jurisdiccional y como tal, se plantean las mismas cuestiones que en los procesos estatales. Entre ellas, el control de constitucionalidad y convencionalidad de los actos legislativos que se pretenden aplicar en el litigio que se dirime por arbitraje y su eventual incompatibilidad con normas de rango superior (Constitución y Derecho internacional de los Derechos Humanos).

Así pues, el presente trabajo pretende analizar en profundidad la procedencia del contralor de constitucionalidad y convencionalidad de los actos legislativos en el proceso arbitral.

\section{ARBITRAL}

\section{EL CONTROL DE CONSTITUCIONALIDAD EN EL PROCESO}

\section{II.1. EI control de constitucionalidad en el ordenamiento jurídico uruguayo}

Previo a la aprobación de un acto legislativo, podemos entender que existe una suerte de control previo o preventivo de constitucionalidad. Evidentemente este control no está regulado expresamente en nuestro ordenamiento jurídico y podríamos considerar que tiene el carácter de difuso e inorgánico, en tanto no existe en Uruguay un órgano específicamente creado para efectuar un control previo de constitucionalidad, como si existe en otros países (por ejemplo, a través de tribunales constitucionales). Este control previo lo lleva a cabo el propio legislador al discutir el proyecto de ley, el gremio, las comisiones académicas, el ámbito universitario, y todos aquellos que plantean una posible objeción de inconstitucionalidad y que a veces permite evitar la aprobación de leyes inconstitucionales.

El control posterior de los actos legislativos (leyes y decretos departamentales con fuerza de ley en su jurisdicción) se le atribuye al órgano máximo del Poder Judicial, la Suprema Corte de Justicia (SCJ), a quien le compete el conocimiento y la resolución originaria y exclusiva en la materia, conforme lo dispone el artículo 257 de la Constitución. Por lo tanto, desde su origen, esto es, desde la Constitución de 1934, el sistema de control de constitucionalidad de los actos legislativos en Uruguay es concentrado y judicialista (por oposición a los sistemas difusos o con órganos políticos, como los tribunales constitucionales). 
Esto no implica que se encuentre excluido el control de regularidad constitucional del resto de los actos jurídicos, ya que en realidad el control es mucho más amplio y abarca a todos los actos jurídicos (dependerá del tipo de acto jurídico a quien le competa su análisis constitucional. Por ejemplo, la regularidad de un acto administrativo ante el TCA y la constitucionalidad de un contrato que se pretende hacer valer en un proceso judicial, ante el Juez que conozca en el asunto).

La declaración de inconstitucionalidad de las leyes opera como una garantía fundamental para asegurar la defensa jurídica de la Constitución. Consiste en declarar si existe contradicción entre una norma y la Constitución, y en ordenar que se acate la que sea de grado superior, asegurando el principio de jerarquía de las normas jurídicas.

Se trata por lo tanto de una verdadera esencia de nuestro sistema democrático republicano, una garantía que implica el sistema de contralor de la constitucionalidad de los actos legislativos, en aras de la protección máxima de la Constitución.

El proceso de declaración de inconstitucionalidad fue originalmente reglamentado por la ley Nro. 13.747 del 10 de julio de 1969. No obstante, dicha ley fue derogada tácitamente por la ley 15.982, que aprobó el C.G.P. Actualmente, el proceso de inconstitucionalidad se encuentra reglamentado en dicho ordenamiento procesal (arts. 508 a 523).

Conforme al art. 258 de la Constitución son tres las vías mediante las cuales puede plantearse la inconstitucionalidad: (i) de oficio (el Juez o Tribunal que entienda en el proceso), (ii) de acción (se promueve por vía principal, directamente ante la Suprema Corte de Justicia), (iii) de excepción (supone la existencia de otro proceso en el cual se plantea, por vía indirecta). La "excepción" como tal es una actitud de la parte demandada. Por ello es que se le ha denominado por la doctrina y la jurisprudencia, así como también por el C.G.P, como excepción o "defensa", ya que se admite la proposición por cualquier interesado principal, cualquiera sea su posición procesal.

Ahora bien, el texto constitucional establece, tanto para la vía de excepción como de oficio, que la declaración de inconstitucionalidad se debe plantear en un proceso "judicial".

Esta solución fue consagrada en la Constitución del año 1952 y se ha mantenido inalterada a lo largo de todas las reformas constitucionales. Por lo tanto, a partir del año 1952 y a la fecha (en tanto la Constitución de 1967 mantiene la misma redacción), se han generado grandes dudas interpretativas que han derivado en profundos desarrollos académicos respecto de si es admisible la proposición de la vía de excepción y de oficio ante o por cualquier órgano jurisdiccional. 


\section{II.2. Procedencia de la inconstitucionalidad por la vía de excepción y de oficio en el proceso arbitral}

Analizado desde la óptica técnica, orgánico formal, o desde una interpretación exclusivamente literal del citado art. 258, debería entenderse que nuestra Constitución excluyó la declaración de inconstitucionalidad por vía de excepción o de oficio a todo proceso que no tramite por el Poder Judicial, en tanto únicamente se refiere a proceso "judicial". Por ende, quedaría fuera del ámbito de aplicación cualquier proceso jurisdiccional, ya sea estatal (por ejemplo, el proceso anulatorio ante el Tribunal de lo Contencioso Administrativo) o arbitral.

La problemática que estamos abordando fue originalmente reforzada por la reglamentación del proceso de inconstitucionalidad prevista en la ley Nro. 13.747 el 10 de julio de 1969. Dicha ley refería predominantemente a procedimientos "judiciales"2, lo cual parecía confirmar la interpretación literal del texto constitucional (sin perjuicio de que en uno de sus artículos refiere a "procedimientos jurisdiccionales"3).

Posteriormente, dicha ley fue derogada tácitamente por la ley Nro. 15.892 que aprueba el C.G.P y trae aparejada una gran novedad. En efecto, a diferencia de nuestra Constitución y de la ley que anteriormente la reglamentaba, que delimitaban la procedencia de ambas vías exclusivamente a los procesos tramitados ante los órganos del Poder Judicial, el C.G.P (en redacción que desde el año 1989 a la fecha se mantuvo incambiada) refiere a procedimiento jurisdiccional (art. 508) o directamente a "procedimiento" (sin distinción entre judicial y jurisdiccional, arts. 511, 514, 515, 521 y 523).

Cualquiera de las dos expresiones es más amplia que la que utiliza la norma Constitucional, ya que permite comprender a todos los procesos jurisdiccionales, sin distinción alguna.

\footnotetext{
2 "Artículo 3": (Caso concreto).- Siempre que deba aplicarse, una ley o un decreto de los Gobiernos Departamentales que tengan fuerza de ley en su jurisdicción, en cualquier procedimiento seguido ante los magistrados que ejercen el Poder Judicial (artículo 233 de la Constitución) o ante el Tribunal de lo Contencioso Administrativo, se podrá promover la declaración de inconstitucionalidad. Artículo $5^{\circ}$. (Acción o excepción).- Cuando la declaración de inconstitucionalidad se solicite por las personas a que se refiere el apartado a) del artículo anterior, podrá ser promovida:

1)Por vía de acción, cuando no exista procedimiento judicial pendiente. En este caso deberá interponerse directamente ante la Suprema Corte de Justicia.

2)Por vía de excepción o defensa, que necesariamente deberá oponerse ante el Juez o Tribunal que esté conociendo en dicho procedimiento judicial. " (destacado nuestro)

${ }^{3}$ Artículo 18. (Efectos del fallo).- La declaratoria de inconstitucionalidad hace inaplicable la disposición legal afectada por ella, en los procedimientos jurisdiccionales en que se haya pronunciado.

Si hubiera sido solicitada por vía de acción o principal, la sentencia tendrá eficacia para impedir la aplicación de las normas declaradas inconstitucionales al que ha promovido la declaración y obtenido la sentencia, pudiendo hacerla valer como excepción en cualquier procedimiento jurisdiccional o en el anulatorio del Contencioso Administrativo". (destacado nuestro)
} 
Frente a este escenario, entre un texto constitucional que se mantiene desde el año 1952 y una reglamentación novedosa en el año 1989, se ha planteado la duda - tanto en doctrina como en jurisprudencia - respecto de si las vías de oficio o de excepción (defensa) de inconstitucionalidad son admisibles solo en los procesos que se sustancian ante el Poder Judicial o si, por el contrario, son admisibles en los procesos tramitados ante cualquier órgano jurisdiccional; ajeno al Poder Judicial.

Este aspecto ha sido debatido muy especialmente en los procesos tramitados ante el TCA, órgano jurisdiccional que no integra el Poder Judicial. Al respecto, diversos autores han dedicado profusas páginas al análisis y ha generado interesantes debates académicos en relación a si resulta admisible oponer la excepción de inconstitucionalidad en un proceso tramitado ante el TCA.

En cuanto a la procedencia de estas vías (excepción y oficio) en el proceso arbitral, encontramos la posición de VESCOVI que parece sostener la tesis que rechaza la procedencia de la proposición de la vía de excepción en los procesos arbitrales, fundada en una interpretación literal de la norma constitucional.

VESCOVI (1967), señala que:

La determinación de cuáles son los procesos en los cuales puede plantearse, depende de los diversos sistemas positivos. En general el criterio es amplio, considerándose que no solamente corresponde plantear la inconstitucionalidad, por vía incidental, en un proceso ordinario, como en un juicio especial o extraordinario e inclusive en los procesos de ejecución y en los cautelares (...) Inclusive se ha sostenido la posibilidad de plantear la cuestión en el juicio arbitral, para que los árbitros desapliquen la ley inconstitucional, aunque no que remitan el asunto al órgano a quien se le atribuye competencia concentrada. Esta posibilidad, que podría solamente ser sostenida de acuerdo con los principios generales, como se admite la facultad judicial de declarar la inconstitucionalidad en otros sistemas, sin texto expreso, parece estar excluida, en nuestro derecho, por la letra de nuestra constitución (pp. 142-143).

No obstante, unas páginas más adelante, al analizar si es admisible la vía de excepción en un proceso anulatorio ante el TCA, VESCOVI (1967) señala que "se considera que la expresión procedimiento "judicial" debe entenderse como "procedimientojurisdiccional" lo que parece ser la correcta inteligencia de la norma” (p. 145). Aunque a primera vista parecería un tanto contradictorio, consideramos que el autor probablemente lo estructura desde un esquema de proceso jurisdiccional estatal (por ejemplo, TCA) y por eso razón rechaza la procedencia en el proceso arbitral. 
Asimismo, VESCOVI (1969) en un trabajo posterior y frente a la aprobación de la ley Nro. 13.747 que originalmente reglamentó el proceso de inconstitucionalidad y que establecía en el art. 3: "cualquier procedimiento seguido ante los magistrados que ejercer el Poder Judicial”, ratifica su postura en relación al proceso arbitral señalando que "con esta expresión se excluye la posibilidad de plantearlo en el juicio arbitral, solución a la que llegábamos también antes de la ley”. (p. 369)

En el foro procesal quien se ha manifestado en forma expresa por la admisibilidad de la proposición de la vía de excepción y de oficio por cualquier órgano jurisdiccional del tribunal Estado o por un tribunal arbitral es VALENTIN (2016).

Respecto de la vía de excepción, señala el autor que: "Aunque no es un tema especifico que pretenda abordar extensamente en este trabajo, quiero consignar que, a mi juicio, la proposición de la excepción o defensa de inconstitucionalidad no sólo debe admitirse ante el tribunal Estado sino también ante cualquier tribunal arbitral"' (p. 27)

Y en relación a la vía de oficio, ha manifestado VALENTIN (2016) que:

A mi juicio, por "tribunal" de acuerdo al sentido con que esta expresión es utilizada en el CGP, debe entenderse cualquier órgano jurisdiccional integrante del Poder Judicial o de cualquiera de los sistemas orgánicos del Estado a los que la Constitución atribuye expresamente el ejercicio de función jurisdiccional; así como cualquier tribunal arbitral. Por otra parte, las palabras "cualquier procedimiento jurisdiccional" refieren a cualquier proceso jurisdiccional que se tramita ante esos órganos (p. 34).

Y más adelante el autor lo ratifica:

Entiendo que debe postularse una interpretación ampliatoria de la literal "procedimiento judicial" del texto constitucional, para admitir la proposición de la vía de oficio por cualquier otro órgano jurisdiccional del Estado (por ejemplo, la Corte Electoral cuando actúa en procesos jurisdiccionales). Asimismo, en la línea del CGP, debería admitirse la proposición de esta vía por un tribunal arbitral (p. 35).

Compartimos la postura sostenida por VALENTIN, en el sentido de admitir tanto la proposición de la vía de la excepción o defensa de inconstitucionalidad, así como la vía de oficio en los procesos arbitrales. Defendemos el sentido amplio de la expresión "judicial" que, si bien tiene una connotación orgánica, no necesariamente es restringida al Poder Judicial ya que existen razones de peso para apartarse del tenor literal. 
En este sentido, no parece razonable aferrarse a una interpretación literal o piedeletrista del texto constitucional, cuando precisamente dicha interpretación implica una limitación no solo respecto del derecho de acceso a la justicia sino también del principio de igualdad. Si sostenemos un análisis literal de la norma llegaríamos a la absurda conclusión de que serían admisibles las vías de excepción o de oficio de inconstitucionalidad en un proceso tramitado ante un órgano estatal, mientras que no lo serían en un proceso arbitral. Como señala VALENTIN (2016) no se "asegura un acceso igualitario a la jurisdicción: todos tenemos el derecho a acceder al proceso jurisdiccional en las mismas condiciones." (p. 33).

En efecto, si sostenemos la interpretación literal de la norma constitucional, el principio de igualdad procesal se vería doblemente violentado: primero, porque ni las partes podrían oponer la excepción o defensa de inconstitucionalidad de una ley, ni el tribunal arbitral - de oficio - podría plantearlo. Y segundo, porque en virtud del diseño constitucional uruguayo, que descarta de plano el control a posteriori de actos legislativos difuso, el tribunal arbitral no tendría competencias para conocer y declarar la inconstitucionalidad de una ley "incidenter" y con efecto en el caso concreto, siendo siempre de competencia concentrada, exclusiva y excluyente de la SCJ.

Cabe destacar que en otros países de Latinoamérica se entiende admisible el análisis de la constitucionalidad por parte del tribunal arbitral. En Argentina, dado el sistema difuso de control de constitucionalidad de las leyes, se admite el planteo de inconstitucionalidad de las normas en el proceso arbitral, en tanto no excede la competencia del tribunal arbitral. El Argentino Augusto Mario MORELLO (2010) citado en REYES SINISTERRA y GÓMEZ GÓMEZ (2016, p. 13), señala precisamente que "El punto de partida es que el tribunal arbitral es un tribunal de justicia, aunque no forme parte del poder judicial; la función que cumple es propia de los órganos que cumplen este servicio, aunque pueden no tener todos sus atributos".

En Colombia, sucede algo similar, señalan REYES SINISTERRA y GÓMEZ GÓMEZ (2016) que:

No existe en Colombia alguna normativa que impida interpretar que los tribunales arbitrales no puedan declarar la inconstitucionalidad de una ley. Todos los jueces se hallan habilitados para formular la declaración de inconstitucionalidad, y la sentencia que se dicte en ese sentido produce efectos únicamente entre las partes. En consecuencia, si los árbitros están dotados por ley de idénticas potestades y funciones que los jueces, no existe ninguna razón válida para privarlos del ejercicio del control de constitucionalidad de las normas, con incidencia en el caso concreto sometido a juzgamiento. (p. 17). 
Retomando al panorama uruguayo, nos volcamos hacia una interpretación del texto constitucional que habilite la proposición de la excepción o defensa de inconstitucionalidad ante el tribunal Estado y ante cualquier tribunal arbitral, así como la proposición de la vía de oficio por cualquier otro órgano jurisdiccional del Estado o por un tribunal arbitral.

Cuando el lector se enfrenta a diversas posturas de interpretación, debe optar por la que mejor proteja los derechos sustanciales en juego. En los mismos términos lo señala específicamente para esta problemática VALENTIN (2016): "Entre una interpretación que hace prevalecer el derecho a acceder a un proceso jurisdiccional (el de inconstitucionalidad por vía de excepción) y otra que elige el tenor literal en desmedro de aquél derecho, creo que debe prevalecer la primera." (p. 33)

El planteo de una cuestión de constitucionalidad tiene su fundamento en el Estado de Derecho y debe admitirse ante cualquier tribunal, ya sea estatal o no.

\section{II.3. El procedimiento de la vía de excepción de inconstitucionalidad o de oficio.}

Tratándose de un arbitraje doméstico, corresponde cuestionarse si el procedimiento que debe tramitarse ante un planteo de inconstitucionalidad - ya sea por la vía de excepción o por la vía de oficio -, es el reglamentado en nuestro C.G.P (arts. 508-523).

En efecto, las partes pueden pactar el procedimiento que consideren más conveniente, conforme lo prevé el art. 490 del C.G.P. En tal sentido, por ejemplo, pueden pactar que el procedimiento arbitral seguirá el del proceso ordinario previsto en el C.G.P o, por el contrario, el establecido por las normas de procedimiento del Reglamento de Arbitraje del Centro de Conciliación y Arbitraje, Corte Internacional para el MERCOSUR, Bolsa de Comercio de Uruguay.

Sin perjuicio de ello, el propio art. 490 del C.G.P prevé que para el caso que "nada dijeren o en cuanto no hubiese sido objeto de previsión especial en el procedimiento señalado, se aplicarán por los árbitros las disposiciones establecidas en este Código para el proceso ordinario".

Pese a que dicha norma remite exclusivamente a las disposiciones del proceso ordinario, concluimos que serían de aplicación las disposiciones previstas en el C.G.P respecto del proceso de inconstitucionalidad de las leyes (arts. 508-523). Por lo tanto, la parte en el proceso arbitral deberá formular la solicitud de declaración de inconstitucionalidad por escrito, con todos los requisitos previstos por el art. 512 C.G.P. 
Ahora bien, ¿qué sucede si el árbitro o tribunal arbitral rechaza el planteo de inconstitucionalidad por la vía de excepción?

Nuestro ordenamiento procesal prevé el recurso de queja por denegación de la excepción de inconstitucionalidad (arts. 262 a 267 C.G.P) y así lo establece expresamente el art. 513 numeral 2 del C.G.P: "513.2 Cuando el que usó de la defensa o excepción de inconstitucionalidad se agraviare de la denegación y omisión del trámite, podrá recurrir por vía de queja conforme con lo dispuesto por los artículos 262 a 267."

Según nuestra ley procesal el recurso de queja se presenta dentro del plazo de cinco días siguientes al de la notificación de la providencia denegatoria y ante el mismo tribunal que la dictó. Una vez presentado el recurso de queja, y de conformidad con lo previsto en el art. 264 C.G.P, el mismo tribunal podrá revocar por contrario imperio la resolución impugnada o, por el contrario, el tribunal lo remitirá sin más trámite al superior.

Lo que no está regulado en el C.G.P es la hipótesis del arbitraje, por lo que nos cuestionamos si resultaría admisible la tramitación del recurso de queja por denegación de la excepción de inconstitucionalidad y en cuyo caso, quién sería el "tribunal superior" al que refiere el art. 264 C.G.P. En tal sentido, ¿es posible que exista otro tribunal que pueda resolver si se admite o no el recurso de queja por denegación de la excepción de inconstitucionalidad?

Por un lado, podríamos entender que - como sucede en el arbitraje -, frente a una resolución del árbitro que las partes no están de acuerdo, estas podrán recurrirla frente al propio árbitro, pero no hay instancia de análisis por parte de un tribunal de alzada mediante la interposición de un recurso de apelación. Por lo tanto, frente al rechazo de la excepción de inconstitucionalidad planteada por una de las partes, no habría opción de acudir al recurso de queja que necesariamente implica el análisis por un tribunal diferente y dentro del Poder Judicial.

Pero, por el otro lado, y si entendemos que resultaría de aplicación al arbitraje la reglamentación del proceso de inconstitucionalidad prevista en el C.G.P (art. 490), debemos considerar que dentro de dicha reglamentación está expresamente establecido que, en caso de denegatoria de la defensa o excepción de inconstitucionalidad, quien se agraviara podría recurrir al recurso de queja. Por lo tanto, el tribunal arbitral debería remitir sin más trámite las actuaciones relativas al plateo de inconstitucionalidad al "tribunal superior", que en este caso debería ser el tribunal que hubiere conocido si no hubiese mediado el arbitraje. 
Evidentemente, este punto no está regulado expresamente por el C.G.P, lo que entendemos que permitiría sostener válidamente ambas posturas u otras interpretaciones posibles.

\section{II.4. La vía de acción y el proceso arbitral}

Independientemente de la vía de excepción, la parte interesada en la desaplicación de la ley o decreto departamental en un proceso arbitral, podría solicitar su inconstitucionalidad por la vía de acción, directamente ante la SCJ. Esto le permitiría sortear las dificultades de rechazo por parte del árbitro de la vía de excepción y hasta el rechazo de la tramitación del recurso de queja.

Se podría plantear el escollo que prevé el art. 510.1 del C.G.P en tanto dispone que únicamente procede esta vía de acción "cuando no existiere procedimiento jurisdiccional pendiente". Por lo tanto, si se entendiere aplicable esta norma, en caso de existir un proceso arbitral pendiente, el interesado quedaría imposibilitado de plantear la inconstitucionalidad por la vía de acción. No obstante, entendemos que la Constitución no dispone ninguna limitación al planteo de la vía de acción, sino que esta limitación está en una norma de rango legal (C.G.P). Por lo tanto, el interesado podría plantear por la vía de acción, directamente ante la $\mathrm{SC}$, la inconstitucionalidad de la norma jurídica que pretende desaplicar en el proceso arbitral y la inconstitucionalidad del art. 510.1. del C.G.P, por limitar la vía de acción.

Por otra parte, para el caso que una de las partes del proceso arbitral solicite por la vía de acción la inconstitucionalidad de una norma que se quiere aplicar en el arbitraje, surge también la interrogante de si el árbitro o tribunal arbitral debe dictar el laudo arbitral o esperar a que la SCJ se pronuncie respecto de la inconstitucionalidad planteada por una de las partes.

En el supuesto de que el proceso se encuentre en el plazo para el dictado del laudo arbitral, y las partes se pusieran de acuerdo en solicitar la suspensión del procedimiento hasta tanto se resuelva la inconstitucionalidad en la SCJ, no se generaría ningún inconveniente.

El problema surge cuando no existe acuerdo de partes para la suspensión del procedimiento arbitral. En este caso es cuestionable si el árbitro puede, en función de las facultades de dirección del proceso arbitral, aguardar la resolución de la SCJ respecto de la solicitud de declaración de inconstitucionalidad por la vía de acción, para luego dictar el laudo. 
Evidentemente, esto es muy complejo ya que dentro de las causales de nulidad del laudo se encuentra precisamente la de haberse dictado fuera del plazo (art. 499.1 C.G.P.), por lo que la opción de dilatar el dictado del laudo arbitral sería muy riesgosa.

En esta hipótesis, también cabe cuestionarse qué sucede si, luego de que el laudo arbitral ha quedado firme, la SCJ hace lugar a la inconstitucionalidad solicitada por la vía de acción, que hubiese tornado inaplicable una norma jurídica que se aplicó en el arbitraje.

En algunos países latinoamericanos se ha instalado ya hace muchos años el debate respecto de la procedencia de la acción de tutela o de amparo contra el laudo arbitral. Por ejemplo, la Corte Constitucional en Colombia ha admitido su procedencia.

En Uruguay, el amparo legal tiene una cortapisa para promoverlo contra un laudo arbitral, en tanto se excluye del ámbito de aplicación: “A) Contra los actos jurisdiccionales, cualquiera sea su naturaleza y el órgano del que emanen ” (ley Nro. 16.011, art. 1). Podría eventualmente evaluarse la opción de un amparo constitucional con fundamento en los arts. 7, 72 y 332 de la Constitución. Pero, en definitiva, no existe una solución normativa expresa frente a este supuesto.

\section{II.5. Casos prácticos relevados en Uruguay}

En nuestro país, existen antecedentes jurisprudenciales donde se ha planteado por la vía de excepción la inconstitucionalidad de una norma que se pretende aplicar en un proceso arbitral y el tribunal arbitral ha acogido el planteo de la inconstitucionalidad, lo que ratifica la tesis formulada en el presente trabajo.

En consecuencia, en esos casos se ha suspendido la tramitación del proceso arbitral, elevándose las actuaciones a la SCJ, quien ha asumido competencia y admitido el planteo de constitucionalidad formalmente (en tanto consideró que procedía la vía de excepción).

En el año 2019 se planteó en un proceso arbitral la inconstitucionalidad del art. 499 del C.G.P en tanto no se prevé la apelación del fallo arbitral. Por Sentencia Nro. 600/2019 de fecha 08/04/2019, la Suprema Corte de Justicia por unanimidad, desestimó el excepcionamiento de inconstitucionalidad promovido, por cuanto entendió que la doble instancia en materia civil no integra el debido proceso constitucional, remitiéndose a los argumentos desarrollados en las Sentencias Nos. 220/2017 y 691/2018, dictadas por dicho órgano. 
Asimismo, con posterioridad se planteó en el mismo proceso arbitral y por la misma parte que había planteado la inconstitucionalidad del art. 499 del C.G.P por la doble instancia, la inconstitucionalidad del art. 497 del C.G.P que refiere a los gastos del proceso y que no prevé la auxiliatoria de pobreza en el proceso arbitral.

Por Sentencia Nro. 2.273/2019 de fecha 07/11/2019, la SCJ declaró inadmisible la excepción de inconstitucionalidad interpuesta, en aplicación de lo dispuesto por el art. 512.2 del C.G.P, manifestando que:

Aún cuando son diferentes las normas señaladas como inconstitucionales en las excepciones, en el proceso de inconstitucionalidad rige plenamente el principio de economía procesal del que se derivan los propios de eventualidad (planteo simultáneo y no sucesivo de las defensas), concentración de los actos procesales y de preclusión, en razón de lo cual se encuentra vedado el planteamiento de sucesivas cuestiones de inconstitucionalidad.

Dejamos planteada la dudosa constitucionalidad del art. 512.2 C.G.P, que prohíbe el planteo de sucesivas inconstitucionalidades, en tanto la Constitución no lo restringe y se establece una limitación por la vía legal. Sin perjuicio de que hay quienes sostienen que en dicha norma radican los fundamentos legales de la cosa juzgada, el art. 512.2 del C.G.P se contrapone con otra disposición del mismo ordenamiento procesal, esto es, la regla general establecida en el art. 11 del C.G.P, que prevé el derecho de acceso universal a los tribunales y la tutela jurisdiccional efectiva.

\section{EL CONTROL DE CONVENCIONALIDAD EN EL PROCESO ARBI- TRAL.}

\section{III.1. El control de convencionalidad en el ordenamiento jurídico uruguayo}

Como es posible analizar el control de constitucionalidad y su procedencia en el proceso arbitral, se plantea también la interrogante respecto del control de convencionalidad.

El control de convencionalidad es un concepto que surge de la propia Corte Interamericana de Derechos Humanos (Corte IDH) y que ha evolucionado, ampliando su contenido y alcance.

Inicialmente implicaba un control de compatibilidad, esto es, de confrontación del derecho interno con la Convención Americana de Derechos Humanos - comúnmente conocida como el Pacto de San José de Costa Rica - (CADH). Pero luego, se incluyó dentro 
del control de convencionalidad la confrontación con la jurisprudencia general de la Corte IDH, así como la interpretación que la Corte IDH hace de la CADH.

Señala MARURI ARMAND-UGÓN (2018, p. 81) que actualmente es un concepto complejo que comprende los siguientes elementos:

a) Consiste en verificar la compatibilidad de las normas y demás practicas internas con la $\mathrm{CIDH}$, los demás tratados internacionales de los cuales el Estado sea parte, la jurisprudencia y las interpretaciones de la Corte IDH.

b) Es un control que debe ser realizado ex officio por toda la autoridad pública en el ámbito de sus competencias y no solamente por el Poder Judicial.

c) Su ejecución puede implicar la supresión de normas contrarias a la CIDH o bien su interpretación conforme a la $\mathrm{CIDH}$, dependiendo de las facultades de cada autoridad pública.

Por lo tanto, el control de convencionalidad parte también de la idea del "juez interamericano", es decir, que todos los jueces tienen la posibilidad de controlar la convencionalidad de las leyes y de cualquier acto jurídico. Asimismo, parte de la idea de que todas las autoridades al ejercer sus atribuciones e incluso los particulares deben cuidar que todos los actos jurídicos sean compatibles con la $\mathrm{CADH}$.

En Uruguay, insertar el sistema de control de convencionalidad genera una cantidad de problemas y desafíos, dado nuestro ordenamiento jurídico interno. Como señala GUERRA (2018): "El control de convencionalidad del ordenamiento jurídico, que en puridad deberíamos estudiar previo al control de constitucionalidad, como lo hace notar ESTEVA GALICCHO, es un fenómeno relativamente novedoso en Uruguay. De hecho, actualmente sigue siendo objeto de debate, por lo que amerita un mayor detenimiento que el control de constitucionalidad" (p. 1103).

En sede jurisdiccional, podemos visualizar dos grandes posiciones antagónicas respecto de su control.

Por un lado, fundado en que el control de convencionalidad no estaría comprendido en la Constitución, se sostiene que el control es difuso y cualquier juez puede dejar de aplicar una ley u otro acto jurídico si entiende que es contrario a la $\mathrm{CADH}$.

Por otro lado, y en tanto la gran mayoría de los casos de inconvencionalidad de una ley son, además, casos de inconstitucionalidad, se sostiene que el control de convencio- 
nalidad de actos legislativos es concentrado, siendo exclusivamente competente la SCJ. Pero, si se tratara de un control de regularidad de cualquier otro acto jurídico que no sea una ley o decreto departamental con fuerza de ley en su jurisdicción (por ejemplo, de un contrato en el que se discute si sus cláusulas son ajustadas a la CADH o no), el control de convencionalidad sería difuso y podría efectuarlo cualquier juez.

RISSO (2016, p. 200) se afilia a esta segunda tesis señalando:

En este esquema, y con las dudas que siempre genera adecuar algo nuevo al derecho anterior, entiendo que la solución adecuada conforme nuestra Constitución, consiste en que en los casos de desaplicación judicial de una disposición legal por inconstitucional o inconvencional, la competencia judicial está concentrada en la Suprema Corte de Justicia.

De todas formas, corresponde aclarar, por haber generado dudas en el pasado, que lo único que ingresa dentro de la excepción es lo referido a la declaración jurisdiccional de inconstitucionalidad o inconvencionalidad de una ley. Fuera de esto (del caso de la ley) se aplican las consideraciones generales y cualquier juez resolverá las contradicciones entre la Constitución o el DIDH respecto a un acto que no sea una ley o un decreto con fuerza de ley en su jurisdicción de los Gobiernos Departamentales; interpretará "desde" la Constitución y "desde” el DIDH; superará las omisiones inconstitucionales o inconvencionales del orden inferior mediante la integración; y será competente para los casos de responsabilidad civil por la violación de la Constitución o del DIDH.

Actualmente, la doctrina mayoritaria adhiere a esta postura, en el sentido de que la competencia para resolver la cuestión de convencionalidad de actos legislativos es exclusiva de la SCJ, equiparándola al control de constitucionalidad en lo que a competencia y vías refiere.

Respecto de la confrontación del derecho interno con la jurisprudencia general de la Corte IDH, RISSO (2018, p. 372) destaca la necesidad de conocer los pronunciamientos de la Corte IDH, aunque no sean obligatorios por sí mismos. Señala el autor que esta posición fue aceptada por la SCJ, al referir a la importancia de la jurisprudencia internacional en la Sentencia Nro. 365/2009. 


\section{III.2. Procedencia de la inconvencionalidad en el proceso arbitral}

Trasladando los conceptos manifestados en relación al control de constitucionalidad, concluimos que es también admisible el control de convencionalidad ante cualquier tribunal, ya sea estatal o arbitral, por tratarse de un principio básico del Estado de Derecho.

Respecto del proceso arbitral, se puede plantear la discusión en relación a si el control de convencionalidad de los actos legislativos (leyes y decretos departamentales con fuerza de ley en su jurisdicción) lo puede realizar el propio árbitro o tribunal arbitral, o debe necesariamente entender la SCJ, por ser la única competente para resolver una cuestión de inconvencionalidad. Siguiendo a la doctrina mayoritaria, se debería concluir que el control de convencionalidad de actos legislativos es de carácter concentrado, debiendo únicamente entender la SCJ.

Ahora bien, se plantea la interrogante respecto de si resultan aplicables al control de convencionalidad las disposiciones constitucionales (arts. 256 y ss.) y procesales (arts. 508 - 523 C.G.P) que regulan el proceso de inconstitucionalidad. Sobre este punto, consideramos que sería legítimo sostener que rigen las mismas disposiciones antes referidas para el control de convencionalidad, ya que habitualmente los casos de inconvencionalidad son también de inconstitucionalidad (salvo, por ejemplo, en el caso que se alegue que la Constitución es contraria a la $\mathrm{CADH}$ ), por lo que se verificaría una suerte de yuxtaposición normativa.

Por lo tanto, este control de convencionalidad de los actos legislativos podría verificarse en los procesos arbitrales ya sea por la vía de excepción, así como la vía de oficio. En estos casos, el árbitro o tribunal arbitral debería: a) admitir por la vía de excepción un planteo de inconvencionalidad, suspender el proceso arbitral y elevar las actuaciones a la SCJ para su resolución; b) plantear de oficio la inconvencionalidad de una norma jurídica que no sea compatible con la $\mathrm{CADH}$ (o eventualmente, la jurisprudencia de la Corte IDH) y que se pretende aplicar en el proceso arbitral, suspender dicho proceso y elevar las actuaciones a la SCJ.

Se podría complejizar la situación si, el árbitro o tribunal arbitral, denegara el planteo de inconvencionalidad por la vía de excepción. Aquí nuevamente podrían ser trasladables, y sin perjuicio de ser opinable, las consideraciones analizadas para el control de constitucionalidad, a las cuales nos remitimos. 


\section{REFLEXIONES FINALES}

El control de constitucionalidad de leyes y decretos departamentales con fuerza de ley en su jurisdicción se encuentra regulado en nuestra Constitución de forma escueta y trae aparejado ciertas dudas interpretativas, que han sido relevadas por la doctrina y jurisprudencia.

Evidentemente la redacción del art. 258 de la Constitución al calificar al proceso como "judicial" incorpora una limitante para la proposición de la vía de excepción de inconstitucionalidad o la vía de oficio ante órganos jurisdiccionales ya sea estatales o arbitrales.

En relación al proceso arbitral, son diversas las cuestiones de debate que se pueden plantear respecto del control de constitucionalidad y convencionalidad, lo cual genera grandes desafíos interpretativos, dada la falta de regulación en nuestro ordenamiento jurídico.

Si bien se han relevado antecedentes jurisprudenciales, donde el tribunal arbitral ha acogido la excepción de inconstitucionalidad, suspendiendo el proceso arbitral y elevando las actuaciones a la SCJ, quien ha admitido formalmente el planteo y asumido competencia, la cuestión aún no está resuelta.

La falta de regulación deja también en evidencia otras problemáticas que se suscitan al analizar esta temática, por ejemplo: cuáles son las consecuencias de que el tribunal arbitral rechace un planteo de inconstitucionalidad o inconvencionalidad solicitado por la vía excepción y la discutible procedencia del recurso de queja por denegación de la excepción de inconstitucionalidad o inconvencionalidad en el trámite de un proceso arbitral.

Sin perjuicio de esta problemática, nos volcamos hacia una interpretación que habilite el control de constitucionalidad y convencionalidad, tanto por la vía de excepción como la de oficio, ante cualquier tribunal ya sea estatal o arbitral, por tratarse de un principio básico del Estado de Derecho.

De lo contrario, los sujetos que canalizan sus litigios por la vía alternativa del arbitraje, verían obstaculizada la posibilidad de plantear una cuestión de constitucionalidad o convencionalidad de un acto legislativo en el proceso arbitral, violentándose no solo el principio de igualdad, sino las bases de un Estado de Derecho. 


\section{BIBLIOGRAFÍA CONSULTADA.}

CARDINAL, Fernando y LABAT, Santiago (2018). "Sistemas de control de constitucionalidad de las leyes y la evolución histórica en nuestro Derecho Positivo", en Procesos Constitucionales, FCU, Montevideo.

CHEDIAK, Jorge y NICASTRO, Gustavo (2018). "Legitimación activa en el proceso de declaración de inconstitucionalidad de la ley por las vías de acción y de excepción”, en Procesos Constitucionales, FCU, Montevideo.

DE HEGEDUS, Margarita (2018). "Proceso de inconstitucionalidad de la ley. Vías para obtener su declaración. Procedimento", en Procesos Constitucionales, FCU, Montevideo.

DELPIAZZO, Carlos (2018). “Alcance y desafíos del control de constitucionalidad”, en Procesos Constitucionales, FCU, Montevideo.

DURÁN MARTÍNEZ, Augusto (1998). "La declaración de inconstitucionalidad de las leyes por vía de excepción y la acción de nulidad ante el Tribunal de lo Contencioso Administrativo", en Estudios de Derecho Constitucional, Ingranusi Ltda., Montevideo.

DURÁN MARTÍNEZ, Augusto (2015). "Legitimación en el proceso de inconstitucionalidad de actos legislativos", en Estudios de Derecho Administrativo, N 12, La Ley Uruguay, Montevideo.

GOMES, Fernando (2018). “Objeto del proceso de inconstitucionalidad de la ley. Actos pasibles de ser declarados inconstitucionales", en Procesos Constitucionales, FCU, Montevideo.

GUERRA, Walter (2010). "Nuevo proceso laboral. Fundabilidad y su constitucionalidad y convencionalidad" en Nuevas especialidades del proceso sobre materia laboral: Ley no. 18.572, FCU, Montevideo.

GUERRA, Walter y GUERRA, Martin (2018). Apelación y segunda instancia. Un derecho con fuente en la Constitución y en el Derecho Internacional de Derechos Humanos" en Procesos Constitucionales, FCU, Montevideo.

MARURI ARMAND-UGON, Sofía (2018). "El control de convencionalidad" en Revista De Derecho, 17(34). Disponible en: http://revistas.um.edu.uy/index.php/revistaderecho/article/view/417

NICASTRO, Gustavo (2018). "El proceso de declaración de inconstitucionalidad de la Ley. Cuestiones relevantes en la Jurisprudencia de la Suprema Corte de Justicia”, en Procesos Constitucionales, FCU, Montevideo.

REYES SINISTERRA, C. C. y GÓMEZ GÓMEZ, C. C. (2016) “Control de constitucionalidad por los tribunales arbitrales en Colombia” en Revista de Derecho Privado, Nro. 56, Universidad de los Andes, Colombia. Disponible en: http://dx.doi.org/10.15425/redepriv.56.2016.16

RISSO, Martin (2016). "El control de convencionalidad”, en Revista de Derecho Público, Número 50, FCU, Montevideo. 
RISSO, Martin (2018). "El control de constitucionalidad de las leyes y el principio de convencionalidad" en Procesos Constitucionales, FCU, Montevideo.

SÁNCHEZ CARNELLI, Lorenzo (2005). Declaración de inconstitucionalidad de actos legislativos, $1^{\mathrm{a}}$ edición, F.C.U., Montevideo.

SARLO, Oscar (2018). "Jurisdicción constitucional y argumentación en el Derecho Uruguayo", en Procesos Constitucionales, FCU, Montevideo.

VALENTIN, Gabriel (2015). "Cuatro cuestiones sobre el proceso de inconstitucionalidad de la ley", en Estudios de Derecho Administrativo, №12, La Ley Uruguay, Montevideo.

VÁZQUEZ, Cristina (2018). "Vías para promover la declaración de inconstitucionalidad de actos legislativos", en Procesos Constitucionales, FCU, Montevideo.

VÉSCOVI, Enrique (1990). "Proceso de inconstitucionalidad", en Curso sobre el Código General del Proceso, Tomo II, $2^{\mathrm{a}}$ reimpresión, F.C.U., Montevideo.

VÉSCOVI, Enrique (1969). "El proceso de inconstitucionalidad de la ley en el derecho uruguayo", en Revista Argentina de Derecho Procesal, N ${ }^{\circ} 3$, Argentina.

VÉSCOVI, Enrique (1967). El proceso de inconstitucionalidad de la ley, Cuadernos, Facultad de Derecho y Ciencias Sociales, $N^{\circ} 18$, Montevideo.

Fecha de recepción: 10 de abril 2021 Fecha de aprobación: 29 de abril 2021 